\title{
REVIEW
}

\section{Literature of Ambiguity}

\section{Reading Simone de Beauvoir's Fiction}

Ulrika Björk: Poetics of Subjectivity: Existence and Expression in Simone de Beauvoir's Philosophy. Philosophical Studies from the University of Helsinki 21. Helsinki: Helsinki University Print, 2008. 222 pp. I в в N 978952-10-5134-0

Simone de Beauvoir is known for an original philosophical method that allows philosophers to convey ambiguity and temporality of lived experience in literary form. Further, Beauvoir did not acknowledge herself as constructing philosophical theories, but instead insisted that there is no divorce between philosophy and life. Paradoxically, her unique insight into the method of philosophy made the reception of her work harder. Indeed, even today, it is not easy to organize Beauvoir's work: Among others, for instance, Professor Margaret A. Simons, the editor of Philosophical Writings. Simone de Beauvoir (Beauvoir series. University of Illinois Press, 2004), comments that assigning texts to different titles such as "literary," "philosophical writing," or "political" runs against Beauvoir's own philosophy - but that publishing her texts simply in chronological order, would be even more problematic. Ulrika Björk's doctoral thesis Poetics of Subjectivity: Existence and Expression in Simone de Beauvoir's Philosophy concerns just this problem with labels: What is the relation between philosophical texts and literature? What happens in Beauvoir's literary texts, and how do they manifest her philosophy - or more precisely her conception of subjectivity? What can literature express that cannot be said in philosophy? Respectively, some of these questions can be found also in the heart of aesthetics.

The approach Björk takes in her doctoral thesis relates back to antiquity and to the debate concerning the value of poetics. Aristotle argued that tragedy is more philosophical than history. Whereas history reports what has happened, drama sets up the scene for what might have happened. Furthermore, history is concerned with singular events, tragedy has universal value.

Against this Aristotelian background, the reading of Simone de Beauvoir's non-philosophical oeuvre, like her novels and diaries, as philosophi- 
cal seems like a reasoned project. Björk's point is in showing through the fictional and autobiographical writings of Beauvoir that they are not only deeply philosophical but, further, deepen the philosophical issues of the meaning of ambiguity and subjectivity in a way Beauvoir's directly philosophical writings are not able to do. In demonstrating this, Björk is also showing how de Beauvoir is positioning herself against the division made in antiquity: Tragedy and drama may be more philosophical than history, but it is the division of singular and universal into two different realms that is at stake here.

Björk wishes to bring to surface, how the reason for Beauvoir to dwell in literature, lies in the division into universal and singular that was set out already in antiquity. Literature, drama - in a word, poetics - may be philosophical, but the true question is in the showing how it can be simultaneously universal and singular. Beauvoir claimed that human existence must be viewed from both perspectives, or, in Søren Kierkegaard's terms, from the perspective of temporality and eternity (p. 20). In order to show how this paradoxical "poetics of subjectivity" actually works, Björk has to clarify Beauvoir's philosophical position, starting from her understanding of ambiguity. But first, how does Björk's reading relate to the previous research on Beauvoir?

Beauvoir is far from being a thoroughly researched and discussed figure - for instance, there is a recent new translation of The Second Sex in English. For example Toril Moi's Simone de Beauvoir: The Making of an Intellectual Woman (1994) presents a reading of the person Simone de Beauvoir as an intertextual web of her philosophical, fictional, biographical, and epistolary texts. Björk accentuates that she does not share Moi's treatment where "life" and "text" are collapsed into one and same. Instead, she points out that her study can be associated into a tradition that began with Michèle Le Doeuff's and Simons' studies - and also Sara Heinämaa's - where phenomenological and existential aspects of Beauvoir's work are emphasized. This becomes evident in chapters two and three, where Björk reads Beauvoir against Husserl and Merleau-Ponty - but not Heidegger; as Björk also takes a step back from Heideggerian interpretations of Beauvoir, as presented recently by, for instance, Eva Gothlin (p. 53).

Conversely, also the title of the dissertation clarifies Björk's position within Beauvoir-studies. Björk writes about the title, "[Poetics of Subjectivity] refers both to the systematic relation between Beauvoir's existential and phenomenological notion of subjectivity and her literary works and to her articulations of a creative mode of using language, especially in the 
novel." (21). Within feminist studies, there are researchers underlining the connection between Beauvoir's philosophy and her literary writing. However, the groundbreaking study by Kate and Edward Fullbrook calls, as Björk clarifies, Beauvoir's unique method "literary-philosophical" and underlines the unity of Beauvoir's trains of thought in philosophy and literature. For Björk, there is no such unity. Literature cannot be reduced to philosophy. In addition, she remarks that the word "method" carries a specific significance. Within French existential-phenomenological tradition, method is related to epoché, and the transcendental reduction Beauvoir was not only familiar with the conception of radical shift in attitude, but that it was operative in her own philosophy. Method is thus reserved for this existential-phenomenological shift, where "metaphysical" meaning of subjectivity is revealed.

Now, back to the beginning. Why is Beauvoir turning toward literature? The difference between literature and philosophical texts has been reflected upon by the philosopher herself very explicitly in "Literature and Metaphysics", an essay published originally already in 1946 in Les temps modernes. Traditionally, Beauvoir's philosophy has been characterized as non-systematic: she is specifically opposed to Hegelian "system building" philosophy. The problem with the Hegelian system is in the reduction of the individual into an abstract moment in the history of absolute spirit. Instead, a renowned example of singular experience and objective truth in the history of philosophy is Descartes' cogito. Björk writes how the singular universal has different emphasis depending on the problem at hand. "Fundamentally, the singular universal implies that the truth of human existence can only be known [connu] in and through one's own experience in reality" (p.34). Personal experience that can be communicated to others; "literary work can take the role of the singular universal." (ibid.). Her literary work refers both to autobiographical literature and novels, but the former presents historical universality through the singular perspective of autobiography. This $I$ becomes specifically the woman: The reader is invited to identify with the singular perspective of the autobiographer and share the universality that underlies singular, feminine, or masculine existence (p.38).

In the first chapter, Björk explains Beauvoir's notion of existentialism, which she defined as philosophy of ambiguity, by reading The Ethics of Ambiguity (Pour une morale de l'ambiguïté, 1947). The concept of ambiguity is a notion that attempts to describe the fundamental ambivalence that determines our lives; that humans are, unlike plants or non-human animals, able to know that life is simultaneously movement toward 
death. Thus, humans can be paradoxically both tied to the immediacy of their situation, and, at the same time, distance ourselves from it; change perspective into understanding ourselves as transcendent. In addition to the experience of being infinite and finite, there is also the experience of being "at once separate from and bound to other human beings" (p. 42). Here, Björk reads Beauvoir as continuing to elaborate the central problem in phenomenological tradition, namely the question of intersubjectivity. And as Björk's thesis eventually shows, there will also be certain differences between Beauvoir and the existential phenomenology's approach.

Along intersubjectivity, Björk points out how the phenomenological tradition accentuates temporality. Time-consciousness can be seen as the most fundamental consciousness, as it presupposes all other consciousness (p.110). For Husserl, objective time has its origin in the subjective experience. Björk argues that Beauvoir's notion of ambiguity implies temporality and "the tension between an experience of infiniteness and finitude; between universality of one's existence, and the fact of one's singular life and death" (p.113). Concerning the temporality, Björk shows that the concept of feminine becoming, as presented in The Second Sex (La deuxième sexe, 1949), contributes to the phenomenological conception of temporality. This is the idea that women "have to become subjective, or become what they ontologically 'are': beings of change and transcendence, necessity and possibility, determination and freedom in their concrete singular lives" (p.158).

What kind of literature did Beauvoir appreciate? What Beauvoir criticized were "closed systems or structures of thought that cannot account for life's facticity and change, or that fail to account for the concrete meanings of existence as ambiguous and paradoxical" (p. 125). Literature is a privileged form to account for these meanings. As for herself, Beauvoir mentions in Prime of Life (La force de l'âge, 1960) influential authors of "metaphysical novels" such as Ernest Hemingway and William Faulkner. Regarding Beauvoir's radical ideas concerning the abilities of literature, it is interesting to note that the conception of literature was, according to Björk, pretty clear-cut: instead of turning toward tragedy, Beauvoir saw the novel and autobiography as the forms that could best communicate the singular universal. Clearly, tragedy is bound to the ancient notion of fate, which contradicted the existentialist emphasis on individual choice. The most known of the chosen fictional texts are She Came to Stay (L'invitée, 1943) which for Beauvoir enabled her to express her experience of encountering the other. The thematics of interdependence of 
self and other are also discussed in Ethics as well as in the philosophical essay "Pyrrhus and Cineas" ("Pyrrhus et Cinéas", 1944).

In She Came to Stay, one is able to examine to the concrete "event" of intersubjectivity. Björk's fifth chapter concentrates on the reading of the novel. In addition to intersubjectivity, Björk accentuates the notion of becoming subjective. The triangle between Françoise, Pierre, and Xavière is told in the novel through different perspectives, though primarily through Françoise, for whom it is almost impossible to believe that other people are conscious beings (p. 179). But once trapped in a solipsist world, one is unable to have a clearly defined individuality. Learning the boundaries of self and other is the painful and violent process Françoise has to go through - this leads into the "event," scandal, of intersubjectivity.

What is then unique in fictional form that cannot be said in philosophy? Björk's thesis clarifies Beauvoir's conception of expression - how is it that literature has the "ability to express the universal in its singular, temporal, and contingent manifestations"? (p.125). The difference lies in saying and showing: "when direct communication 'speaks' its meaning, indirect communication does not speak, but rather 'shows' or makes meaning manifest by the presence of contingent details and the use of different narrative voices" (p.127). The small details that the novel or autobiographical literature may dwell in are in fact full of meaning. As Björk states in her conclusion, "[t]he contingent and non-significant details of life are crucial in this recreation: the concrete, intimate and singularly lived details of life are, in fact, constitutive for the meaning expressed through the novel and the autobiography. These details are the 'nonsense' in and by which the 'sense' of existence can at all appear" (p. 204).

To conclude, one could say that Björk's thesis clarifies Beauvoir's "ambiguous" philosophy - her poetics of subjectivity - in a clear and enjoyable manner. Björk's reading of her fiction, the details, and "nonsense" that make manifest Beauvoir's philosophy could have had even more space; now they are concentrated especially in the last chapter. Further, it should be underlined that Björk examines the paradoxical question - namely, the possibility of literature to present something philosophy cannot, and yet be philosophy - that arguably is in the heart of aesthetics, too, and therefore can be recommended also to a wider audience than just Beauvoir scholars. 